\title{
Introduction to the CMOT Special Issue on Mathematical Representations and Models for the Analysis of Social Networks within and between Organizations
}

\author{
ALESSANDRO LOMI \\ Lugano, Switzerland \\ email:alx@economia.unibo.it \\ PHILIPPA PATTISON \\ Department of Psychology, University of Melbourne, Australia \\ email:p.pattison@psych.unimelb.edu.au
}

School of Economics, University of Bologna, Italy and School of Communication Sciences, University of Italian,

\section{Introduction}

Organization theories differ considerably in what they represent as the most important properties of the organizational phenomenon (Pfeffer, 1997; Scott, 1998). Sometimes organizations are seen as resource allocation mechanisms (Simon, 1991; Williamson, 1991) that can be designed to substitute markets whenever the price system cannot guarantee desirable collective outcomes (Arrow, 1974). In other circumstances organizations are depicted as the main sources of power and power differences in modern societies (Coleman, 1974; Pfeffer, 1987). Organizations have been differently viewed as containers of routines and decision rules (March et al., 2001; Nelson and Winter, 1986), as stocks of solutions available to the problem of social change (Hannan and Freeman, 1989) and as sets of codes shaping and constraining collective identities (Carroll and Hannan, 2000). Sometimes organizations are treated as complex cognitive constructions (Weick, 1969), as sets of contractual relationships (Gibbons, 2001) or as intendedly rational solutions to incentive problems (March and Simon, 1958; Milgrom and Roberts, 1992). Organizations have been frequently viewed as complex adaptive computational systems (Carley, 2002; Simon, 1969) that are socially situated (Carley, 1995) and goal-directed (Aldrich, 1999). In some other cases it has proven useful to interpret organizations as patterns of decisions emerging from quasi-random flows of problems, solutions and decision-makers (Cohen et al., 1972; Cohen and March, 1976). Institutional theories portray organizations as rationalizing agents and as "recalcitrant" tools of economic, cognitive and cultural control (Selznick, 1948; DiMaggio and Powell, 1983).

One of the key unifying themes of interest to contemporary students of organizations across a variety of substantive research areas and epistemological orientations is the understanding of how different network ties concatenate to shape the evolution of distinct types of social forms and social settings. Examples of such settings include firms, markets, 
industries and states (Breiger, 2002; Cederman, 1997; DiMaggio, 2001; Powell et al., 1996; Rauch and Casella, 2001; White, 2002). As the papers contained in this special issue collectively demonstrate, the interest in networks has sharpened the focus on the development of increasingly sophisticated theoretical accounts of how different types of relations are implicated in a wide range of organizational processes. Examples of such processes include the emergence of new organizational forms (Padgett and Ansell, 1993; Stark, 2001), and the maintenance and erosion of individual and collective identities across levels of analysis (Breiger, 2000; Mische and Pattison, 2000).

Stimulated by these broad concerns, recent years have witnessed a marked increase both in empirical network studies within and between organizations, and in theoretical speculations as to the possible consequences of networks for processes of boundary formation and dissolution around individuals, institutions and social forms. Such studies often are based on - and give rise to-complex relational data structures that call for a parallel growth in the sophistication of mathematical representation and models for the analysis of social networks and network-related processes. The aim of this special issue is to bring to the attention of members of the computational analysis of social and organizational systems community a selected number of innovative and high-quality contributions that illustrate clearly the relevance of network-based models to the study of complex organizations.

\section{Organizations and Social Networks}

Within the organization theory community network-based models and methods are generally appreciated for the considerable variety of substantive and analytical issues they help to frame, address and discover. Perhaps less generally appreciated — but just as valuable—are the many problems, substantive, analytical and theoretical, that networks concepts pose when adopted as a general strategy for theory building and testing. One of the main ideas behind this special issue is that the unique value of network-based models rests exactly in this complex production of problems and solutions that network analysis continues to supply to students of organizations.

Extensive empirical evidence is now available that demonstrates the distinct contribution of network-based models to our understanding of organizational behavior across virtually all levels of analysis spanned by traditional organizational research. Comprehensive reviews of this evidence can be found in recent articles (Borgatti and Foster, 2003), books (Kilduff and Tsai, 2003; Monge and Contractor, 2003), and in a number of book chapters that explore and attempt to systematize the various areas of overlap between organizations and social networks (Baker and Faulkner, 2002; Burt, 2000; Kilduff and Corle, 2000; Raider and Krackhardt, 2002). Considered together, these very extensive reviews suggest that it difficult to identify an area of organization studies that has not been affected-more or less directly - by innovation and progress in the analysis of social networks. From microorganizational studies of processes related to perceived role similarity (Krackhardt and Porter, 1986) and personality traits (Burt and Jannotta, 1998; Mehra et al., 2001), to macrosociological studies of interorganizational fields, niches, and markets (Burt and Talmud, 1993; DiMaggio, 1986; DiMaggio and Powell, 1893; Podolny et al., 1996; White, 2002) 
it is hard to overestimate the significance that networks models, technologies and imagery have had in shaping current organizational theory discourse.

Yet, as Douglas White and coauthors point out in one of the papers included in this special issue, "[O]rganizational theory has embraced network analysis, but in a potentially limiting manner." The main reason behind this conclusion-these authors argue-is that networks continue to be seen as proto-organizations, a kind of primordial soup of shapeless relationships and fluid dependencies out of which "formal" organizations might eventually emerge. But networks are not the primitive stage of organization. All complex organizations are networks in the sense that they can be viewed as "[P] atterns of roles and relations" (Baker, 1992:399). While this is an important-if implicit-factor limiting the value of current network models for organizational research, it is by no means the only factor. In organization studies - and particularly in the study of business firms - networks are frequently viewed in an almost opposite way, that is as complete, well-bounded "forms" of governance of contractual relationships and business transactions. Studies in this perspective typically compare the functionalities, benefits, rationality, performance and welfare implications of networks with those of competing but similarly generic "forms" such as, for example, "markets" and "hierarchies." This view of networks as organizational "forms" appears to be surprisingly common across otherwise contentious interpretations of the organizational world (see for example Perrow, 1993; Williamson, 1991). The problem in this case seems to reside in the fact that this view of networks is based on typological assumptions about "forms" as global configurations of network ties. But rather than simply assume their global structure a priori, patterns of ties within and across multiple networks are exactly what a relational approach to organizations would like to discover and perhaps interpret (White et al., 1976). Indeed, this goal continues to drive contemporary attempts to develop models for networks that explain global network structure from some appropriately characterised patterning of ties at more localised levels (e.g, Morris, 2003; Pattison and Robins, 2002; Robins et al., in press).

The papers included in this small collection provide rich and compelling alternatives to these opposite, but similarly inadequate, views of networks as fluid collections of independent dyads, and as coherent global forms of governance. While considerably diverse in terms of styles, substantive issues addressed and methodological orientations, the papers in this special issue show how important organizational dimensions of network ties can be analyzed, and provide clear indications about how such dimensions can be discovered in a variety of empirical settings.

\section{Contents of the Special Issue}

As an aid to the appreciation of the remarkable generality of some of the issues that the manuscripts included in the special issue address, consider carefully the following quote taken from a recent essay by the prominent zoologist Richard Lewontin on the "complications of understanding the evolutionary process" (2003):

"[The] taxonomic space of organisms has a huge number of dimensions, each corresponding to some character that might be used in the characterization of an individual. If 
one looks at the occupancy of such a space, one is struck by the fact that it has a structure to it. Individual organisms are clustered in the space and those clusters are themselves clustered. And there are clusters of clusters of clusters, rather like the stars in the cosmos. The most important thing for the evolutionist is that nearly the entire space is empty, not only when extant organisms are considered, but when all organisms known to have ever existed are considered. The measure of the emptiness of that space is nearly one, and the measure of the occupancy is nearly zero. The real problem for the evolutionist is not to explain the kinds of organisms that have actually ever existed. The real problem for the evolutionist is how it is that most kinds of potential and seemingly reasonable organisms have never existed. The problem is to explain the location of the empty spaces in the clustered assemblage of occupied points."

Contrast it now with the following excerpt from Pierre Bordieu's essay titled "The new capital" (1998:32):

"[S]ocial science should construct not classes, but rather the social spaces in which classes can be demarcated [...] In each case it should construct and discover [...] the principle of differentiation which permits one to reengender theoretically the empirically observed social space. [... ] All societies appear as social spaces, that is, as structures of differences that can only be understood by constructing the generative principle which objectively grounds those differences [...] This structure is not immutable, and a topology that describes the state of the social positions permits a dynamic analysis of the conservation and transformation of the structure of the active properties' distribution and thus of the social space itself."

We are not the first to observe an apparent connection between the position occupied by species in an ecosystem and the position (or role) of groups in social spaces. For example, Luczkovich et al. (2003) have developed this conceptual connection into formal operational models of role equivalence in food webs. However, a number of points are notable in these passages written with very different languages, by authors belonging to very different traditions of academic discourse and probably having very different problems in mind. For the purposes of this introduction, at least five points deserve particular attention. The first is the convergence toward a topological representation of (biological, social) space. The second is the characterization of the organizational structure of that space in terms of some solution to an aggregation problem. The third is the observation that the organizational structure of the topological space is highly differentiated. The fourth is the emphasis placed on the position that the various 'objects' of interest come to occupy within the "classified" space. The fifth and final is the notion that (biological, social) innovation and change should be interpreted as the "occupation of a region of the taxonomic space that has been previously empty" (Lewontin, 2003) or as the "transformation of social space itself" (Bordieu, 1998:32).

The paper by Ronald Breiger and John Mohr speaks directly to the issue of duality between categories (or "taxa") and fields (or "taxonomic space") that the short excerpts that we reported so clearly describe. In the specific context of this work, duality refers to observation that shared memberships of individuals in classes (or groups) induces relationships 
among classes, and therefore create connections across different levels of structure-an insight clearly articulated in Breiger (1974).

Breiger and Mohr introduce a family of widely applicable statistical techniques to understand how institutions "do the classifying." The value of their methodological proposal is illustrated in the context of interorganizational fields. Breiger and Mohr call co-constitution the process by which individual identities and institutional practice shape one another and give rise to shared systems of classification. With their basic model Breiger and Mohr establish a clear connection between the network-analytic notion of structural equivalence and the aggregation of social categories in cross-classification tables. Then they show how this model can be extended to two-mode networks providing specific algorithms that can be used to perform a dual aggregation of social identities and organizational practices-a theme previously explored extensively by both authors individually (Mohr and Duquenne, 1997; Breiger, 2000).

As Aldrich and Whetten noted almost a quarter of a century ago (1981), the study of organizations has moved beyond its traditional concern with single organizations to examine how populations and communities of organizations relate to their environments (see also Hannan and Freeman, 1989). A few years later, DiMaggio and Powell (1983) and Scott and Meyer (1983) began to develop a second and equally consequential conceptual shift: that from environments to organizational fields. In turn, this development stimulated a search for new operational definitions of resource dependence in organizational populations and communities (Pfeffer, 1987). Since the early 90's, a number of predictions have been developed about the relationship between specific dimensions of interorganizational network structures and performance variables of interest to organization sociologists and economists (Burt, 1992). The paper by Patrick Doreian and Kayo Fujimoto is grounded in these theoretical developments in the analysis of organizational environments. Doreian and Fujimoto propose a method for identifying linking pin organizations as structurally unique organizations in interorganizational fields. Their model is based on the intuition that if a unit is a linking pin organization, then it will appear as a singleton in the blockmodel image of the source network. Because being a singleton is not a sufficient condition for a unit to be a linking pin organization, Doreian and Fujimoto, explore the implications of adding additional conditions based on nodal properties of the members of the interorganizational field. The empirical examples that they present illustrate the value and generality of their analytical constructs. Doreian and Fujimoto suggest an instructive comparison by exploring the implications of adopting Burt's indexes of network size, efficiency and constraints as sources of information that could be exploited to characterize linking-pin organizations more reliably. From this point of view, Doreian and Fujimoto suggest a new way to characterize the internal hierarchical differentiation of interorganizational fields by integrating analytical criteria that are based on the apparently contradictory logics of network closure and structural equivalence.

Within organization studies the attention to intercorporate relations has been progressively increasing as a direct consequence of the already observed shift toward a direct concern with the structure of organizational environments (Aldrich and Marsden, 1988; Mizruchi and Schwartz, 1987). At least since the self-aware rise of managerial capitalism and the ensuing separation of ownership and control in large corporations (Berle and 
Means, 1932; Marris, 1967), shared directors on corporate boards have been a resilient feature of advanced financial economies. The analysis of interlocking directorates has helped to articulate a particularly compelling image of how organizations try to manage their environmental resource dependencies by establishing connections with other organizations (Pfeffer, 1987).

Somewhat more recently, the interlock network created by overlapping memberships in corporate boards has been found to affect a wide variety of corporate behaviors, ranging from the response to takeover threats (Davis and Greve, 1997) to the company-specific inclination to acquire other companies (Haunschild, 1993). However, as Davis and Greve write (1997:1): "[W]hile networks are often part of the explanation [...] they are rarely examined explicitly as the link between the action of particular organizations and the collective structure that results." In direct response to this comment, Davis et al. (2003) have recently started to develop a theoretical connection between the structure of the American corporate elite and the now well-known small world phenomenon first discovered by Milgram (1967). Building directly on Watts' formal models for small worlds networks (1999) Davis et al. analyzed cross-sectional samples comprised of thousands of directors serving on the boards of largest US corporations over a 17-year period. In their study Davis et al. (2003) find that the average distance between directors and between firms is much shorter than one would expect given the size of the networks. They also find that this property tends to be insensitive to the significant institutional, economic and corporate changes occurred during the observation period.

Garry Robins and Malcolm Alexander contribute an innovative piece of work to this new line of organizational inquiry on corporate interlocks by exploring the global structure of the small world of boards interlock in the US and Australia. The data analyzed by Robins and Alexander take the usual form of two-mode networks (directors-by-companies). However, unlike Davis et al. (2003), Robins and Alexander do not exploit the inherent "duality of directors in corporate boards" (Breiger, 1974) to transform the original two-mode network into two one-mode networks ("director-by-director" and "company-by-company") and then conduct separate analyses. Rather, Robins and Alexander follow an analytical strategy directly inspired by the logic of mutual constitution that Breiger and Mohr discuss in this issue. Robins and Alexander view corporate boards as overlapping social settings and develop models to analyze individuals and companies jointly. The analysis of two-mode networks does not lend itself easily to direct interpretation (Borgatti and Everett, 1997). The determination of global network features is a more complex endeavor in the context of bipartite graphs than it is in the case of one-mode networks. For example, in bipartite graphs there are three types of geodesic distances that can be computed, and clustering coefficients are non unique. The analytical strategy suggested by Robins and Alexander compares observed sets of relational data to a simulated random graph distribution that is conditional on constraint existing in the actual data. If the infrastructural features of a network are consistent with distributions generated from these constraints-Robins and Alexander argue - then no further assumptions are needed to explain the data. When significant differences are found between the conditional random graph distribution and the actual data, then social processes are at work that bias the data away from what would be expected on the basis of a pure stochastic process and additional assumptions are needed 
to characterize the network formation micro-mechanisms that generate the observations. They adopt this strategy to compare two-mode networks of different sizes and densities and to draw inferences about global properties of the networks. In both the US as well as Australian networks Robins and Alexander find evidence of preferential recruitment that they trace back to contrasting social selection procedures operating within boards, a conclusion that is consistent-at least in part-with the results reported by Davis et al. (2003).

The paper by Douglas White, Jason Owen-Smith, James Moody and Walter Powell concludes the special issue with a focus on the topology of network structures within organizations and organizational fields. Following Granovetter $(1985,1992)$, they argue for the significance of the structural embeddedness of network ties, that is, for the extent to which network partners' mutual contacts are themselves connected to one another. They interpret structural embeddedness in terms of levels of structural cohesion, which can be defined for a network substructure either in terms of its susceptibility to disconnection by removal of nodes or, equivalently, in terms of the degree to which any pair of nodes are connected by independent paths (White and Harary, 2001). In light of their argument for the importance of cohesive substructures, White et al.'s topological focus is on the overlaps among cohesive substructures. They analyse an organisation or organisational field into maximal cohesive substructures at varying levels of cohesion, and define a cone as a set of completely nested substructures of this form, with substructures at higher levels of connectivity inevitably contained within substructures as lower levels of connectivity. They go on to characterise the cohesive macro topology of a network in terms of the overlaps among cones. A mono-cone topology is one in which cones do not overlap, whereas a multi-cone topology comprises multiple intersecting cones, with intersections occurring at varying levels of cohesion. White et al. examine some of the network evolution mechanisms that have been analyzed in the literature (including random, degree-biased, and locally-biased mechanisms) in order to generate some suggestive and interesting propositions about the expected cohesive topology arising from different evolutionary mechanisms. They discuss their propositions in the context of a number of interesting case analyses. Their analysis is only suggestive-since only a handful of such mechanisms have been fully analysed to date-but their approach takes an important step in a core task for organizational network analysis: that of explaining where global network structures come from.

In summary we believe that this special issue illustrates well the attitude of network-based approaches to clarify and reframe central issues in contemporary theories of organizations. It would be reductive to consider the papers included in the special issue only as sophisticated applications of network-based techniques of relational data analysis to a selected sample organizational problems. Each individual contribution explores and develops its own link between theoretical arguments and the algorithmic structure of organizational problems that a network-analytic view helps to reveal. We believe that this shared feature makes the contributions of particular relevance not only to organization theorists interested in network models, but also to CMOT's core readers interested in "[D]etailed computational models of people, tasks and networks interrelated in complex, dynamic, adaptive ecological systems" (Carley and Prietula, 1994:xii). 


\section{Acknowledgments}

We are grateful to the authors who have contributed their time and intellectual energies to this small editorial venture. We feel that we have learned a great deal from their work, and we are grateful for their patience, responsiveness and trust. We are also very grateful to the Editor of CMOT, Kathleen Carley, for her support of this Special Issue and for her exceptional patience during the entire period from inception to realisation. This special issue has been made possible only by the support that we received from an extensive network of colleagues and friends who agreed to serve as reviewers and provided their expert opinion and comments on the various manuscripts that we asked them to read. During the editorial process we had the privilege to count on the advice of: Vladimir Batagelj, Philippe Bonacich, Matt Bothner, Fabrizio Castellucci, Martin Erverett, Katherine Faust, Fabio Fonti, John Martin, Ann Mische, Mark Mizruchi, Bill Richards, John Skvoretz, Tom Snjider, Frans Stokman, and Wenpin Tsai. Some of the authors went well beyond the call of duty by agreeing to review some of the papers that were submitted by other authors. We are grateful to Woody Powell and Ron Breiger for their insightful comments on our introduction. We could not publish all of the fine manuscripts we received, but we would like to extend our gratitude to all the authors who shared their ideas and projects with us. Finally, we would like to acknowledge the superb editorial support provided by Melissa Anderson at Kluwer throughout the development and production of this Special Isssue of CMOT. This Special Issue was conceived, and the initial work begun, while Alessandro Lomi was NATO Senior Research Fellow at the Santa Fe Institute (Santa Fe, New Mexico). The financial support provided by a NATO-CNR Grant and the hospitality of the Santa Fe Institute are gratefully acknowledged, as is financial support to Pattison from the Australian Research Council, and to Lomi from the Italian Ministry of University and Research (MIUR).

\section{References}

Aldrich, H. (1999), Organizations Evolving. Thousand Oaks, CA: Sage Publications.

Aldrich, H. and P. Marsden (1988), "Environments of Organizations," in Neil J. Smelser (Ed.) Handbook of Sociology. Thousand Oaks, CA: Sage Publications, pp. 361-392.

Aldrich, H. and D. Whetten (1981), "Organization Sets, Action Sets and Networks: Making the Most of Simplicity," in P. Nystrom and W. Starbuck (Eds.) Handbook of Organizational Design, Vol. I: Adapting Organizations to their Environments. New York: Oxford University Press, pp. 385-408.

Andrews, S. and D. Knoke (Eds.) (1999), Networks in and Around Organizations. Research in the Sociology of Organizations, Vol. 16. Stamford, CT: JAI Press.

Arrow, K. (1972), The Limits of Organization. New York: Norton.

Baker, W. (1992), "The Network Organization in Theory and Practice," in N. Nohria and R.C. Eccles (Eds.) Networks and Organizations. Boston, MA: Harvard Business School Press, pp. 397-329.

Baker, W. R. Faulkner (2002), "Interorganizational Networks," in J.A.C. Baum (Ed.) The Blackwell Companion to Organizations. Oxford, UK: Blackwell, pp. 520-540.

Berle, A. and G. Means (1932), The Modern Corporation and Private Property. New York: Macmillan.

Bordieu, P. (1998), "The New Capital," in P. Bordieu (Ed.) Practical Reason, Chapter 2: pp. 19-34. Stanford University Press, Stanford, California (Essay originally published as "The New Capital: Introduction to a Japanese reading of State Nobility," in Poetics Today, 12(4), 643-653 (Winter 1991).

Borgatti, S.P. and R. Cross (2003), "A Relational View of Information Seeking and Learning in Social Networks," Management Science, 49, 432-445. 
Borgatti, S. and M. Everett (1997), "Network Analysis of 2-mode Data," Social Networks, 19, 243-269.

Borgatti, S. and P. Foster (2003), "The Network Paradigm in Organizational Research: A Review and Typology," Journal of Management, 29, 991-1013.

Breiger, R.L. (2002), "Poststructuralism in Organizational Studies,” in M. Lounsbury and M. J. Ventresca (Eds.) Social Structure and Organizations Revisited. Research in the Sociology of Organizations. JAI Press/Elsevier Science, vol. 19, pp. 295-305.

Breiger, R.L. (2000), “A Toolkit for Practice Theory,” Poetics, 27, 91-115.

Breiger, R.L. (1974), “The Duality of Persons and Groups,” Social Forces, 53, 181-190.

Burt, R. (2000), “The Network Structure of Social Capital," in R. Sutton and B. Staw (Eds.) Research in Organizational Behavior. Greenwitch, CT: JAI Press, pp. 345-343.

Burt, R.S. (1992), Structural Holes. Cambridge, MA: Harvard University Press.

Burt, R. and J. Jannotta (1998), "Personality Correlates of Structural Holes,” Social Networks, 20, $63-87$.

Burt, R. and I. Talmud (1993), "Market Niche," Social Networks, 15, 133-149.

Cederman, L.-E. (1997), Emergent Actors in World Politics: How States and Nations Develop. Princeton, NJ: Princeton University Press.

Carley, K. (2002), "Intraorganizational Complexity and Computation,” in J.A.C. Baum (Ed.) The Blackwell Companion to Organizations. Oxford, UK: Blackwell, pp. 208-232.

Carley, K.M. (1995), "Computational and Mathematical Organization Theory Perspectives and Directions," Computational and Mathematical Organization Theory, 1(1), 39-56.

Carley. K.M. and M. Prietula (1994), "Computational Organization Theory: An Introduction,” in K. Carley and M. Prietula (Eds.), Computational Organization Theory. Hillsdale, NJ: Lawrence Erlbaum Associates, pp. xi-xvii.

Carroll, G. and M. Hannan (2000), The Demography of Corporations and Industries. Princeton: Princeton University Press.

Cohen, M. and J.G. March (1976), Leadership and Ambiguity. Boston, MA: Harvard Business School Press.

Cohen, M., J. March and J. Olsen (1972), "A Garbage can Model of Organizational Choice," Administrative Science Quarterly, 17, 1-25.

Coleman, J.S. (1974), Power and the Structure of Society. New York: Norton.

Davis, G. and H.R. Greve (1997), "Corporate Elite Networks and Governance Changes in the 1980s'," American Journal of Sociology, 103, 1-37.

Davis, G., M. Yoo and W. Baker (2003), “The Small World of the American Corporate Elite, 1982-2001,” Strategic Organization, 1(3), 301-326.

DiMaggio, P. (2001), “Making Sense of the Contemporary Firm and Prefiguring its Future," in P. DiMaggio (Ed.) The Twenty-First Century Firm. Princeton, NJ: Princeton University Press, pp. 3-30.

DiMaggio, P. (1986), "Structural Analysis of Organizational Fields," in B. Staw and L. Cummings (Eds.) Research in Organizational Behavior, Greenwitch, CT: JAI Press, Vol. 8, pp. 335-370.

DiMaggio, P. and W. Powell (1983), "The Iron Cage Revisited: Institutional Isomorphism and Collective Rationality in Organizational Fields," American Sociological Review, 48, 147-160.

Gibbons, R. (2001), "Firms (and Other Relationships)," in P. DiMaggio (Ed.) The Twenty-First Century Firm. Princeton, NJ: Princeton University Press, pp. 186-199.

Granovetter, M. (1992), "Problems of Explanation in Economic Sociology," in N. Nohria and R. Eccles (Eds.) Networks and Organizations. Boston, MA: Harvard Business School Press, pp. 25-56.

Granovetter, M. (1985), "Economic Action and Social Structure: The Problem of Embeddedness," American Journal of Sociology, 91(3), 481-510.

Hanann, M. and J. Freeman (1989), Organizational Ecology. Cambridge, MA: Harvard University Press.

Haunschild, P. (1993), "Interorganizational Imitation: The Impact of Corporate Interlocks on Corporate Acquisition Activity," Administrative Science Quarterly, 38, 564-592.

Kilduff, M. and K. Corley (2000), “Organizational Culture from A Social Network Perspective,” in N. Ashkanasy, C. Wilderom and M. Peterson (Eds.) Handbook of Organizational Culture and Climate. Thousand Oaks, CA: Sage Publications, pp. 211-221.

Kilduff, M. and W. Tsai (2003), Social Networks and Organizations. Thousand Oaks, CA: Sage Publications. Krackhardt, D. and L. Porter (1986), "The Snowball Effect: Turnover Embedded in Communication Networks," Journal of Applied Psychology, 71, 1-6. 
Lewontin, R. (2003), Four Complications in Understanding the Evolutionary Process. Santa Fe Institute Bulletin, Vol. 18, No. 1 (Winter).

Luczkovich, J., S. Borgatti, J. Johnson and M. Everett (2003), "Defining and Measuring Trophic Role Similarity in Food Webs Using Regular Equivalence," Journal of Theoretical, Biology, 220, 303-321.

March, J.G., M. Schultz and X. Zhou (2000), The Dynamics of Rules: Change in Written Organizational Code. Stanford, CA: Stanford University Press.

March, J.G. and H.A. Simon (1958), Organizations. New York: Wiley and Sons.

Marris, R. (1967), The Economic Growth of Managerial Capitalism. London, UK: Macmillan.

Mehra, A., M. Kilduff and D. Brass (2001), "The Social Networks of High and Low Self-Monitors: Implications for Workplace Performance," Administrative Science Quarterly, 35, 121-146.

Milgram, S. (1967), “The Small World Problem,” Psychology Today, 2, 60-67.

Milgrom, P. and J. Roberts (1992), Economics, Organization and Management. Englewood Cliffs, NJ: PrenticeHall

Mische, A. and P. Pattison (2000), “Composing a Civic Arena: Publics, Projects, and Social Settings," Poetics, 27, 163-194.

Mizruchi, M. and M. Schwartz (Eds.) (1987), Intercorporate Relations: The Structural Analysis of Business. New York: Cambridge University Press.

Mohr, J. and V. Duquenne (1997), "The Duality of Culture and Practice: Poverty Relief in New York City, 1888-1917," Theory and Society, 26, 305-356.

Monge, P. and N. Contractor (2003), Theories of Communication Networks. New York: Oxford University Press. Morris, M. (2003), "Local Rules and Global Properties: Modeling the Emergence of Network Structure," in R.L. Breiger, K.M. Carley and P.E. Pattison (Eds.) Dynamic Social Network Modeling and Analysis. Washington, DC: National Academies Press, pp. 174-186.

Nelson, R. and S. Winter (1982), An Evolutionary Theory of Economic Change. Cambridge, MA: Harvard University Press.

Padgett, J. and C. Ansell (1993), "Robust Action and the Rise of the Medici, 1400-1434," American Journal of Sociology, 98, 1259-1319.

Pattison, P. and G.L. Robins (2002), "Neighbourhood Based Models for Social Networks," Sociological Methodology, 32, 301-337.

Perrow, C. (1993), "Small-Firm Networks," in N. Nohria and R.C. Eccles (Eds.) Networks and organizations. Boston, MA: Harvard Business School Press, pp. 430-444.

Pfeffer, J. (1997), New Directions for Organization Theory. New York: Oxford University Press.

Pfeffer, J. (1987), in M. Mizruchi and M. Schwartz (Eds.) Intercorporate Relations: The Structural Analysis of Business. New York: Cambridge University Press, pp. 25-55.

Pfeffer, J. and G. Salancik (1978), The External Control of Organizations. New York: Harper and Row.

Podolny, J., T.E. Stuart and M.T. Hannan (1996), "Networks, Knowledge, and Niches: Competition in the Worldwide Semiconductor Industry, 1984-1991,” American Journal of Sociology, 102, 659-689.

Powell, W.W., K. Kenneth Koput and L. Smith-Doerr (1996), "Interorganizational Collaboration and the Locus of Innovation: Networks of Learning in Biotechnology," Administrative Science Quarterly, 41(1), 116-45.

Raider, H. and D. Krackhardt (2002), "Intraorganizational Networks," in J.A.C. Baum (Ed.) The Blackwell Companion to Organizations. Oxford, UK: Blackwell, pp. 58-74.

Rauch, J. and A. Casella (Eds.) (2001), Networks and Markets. New York: Russell Sage Foundation.

Robins, G.L., P.E. Pattison and J. Woolcock (in press), "Small and Other Worlds: Global Network Structure Form Local Processes," American Journal of Sociology.

Scott, R. (1998), Organizations: Rational, Natural and Open Systems. Upper Saddle River, NJ: Prentice Hall.

Scott, W.R. and J.W. Meyer (1983), "Organization of Societal Sectors," in J. Meyer and W.R. Scott (Eds.) Organizational Environments: Ritual and Rationality. Beverly Hills, CA: Sage Publications, pp. 129-154.

Selznick, P. (1948), "Foundations of the Theory of Organization," American Sociological Review, 13, 25-35.

Simon, H.A. (1991), "Organizations and Markets," Journal of Economic Perspective, 5(2), $25-44$.

Simon, H. (1969), The Sciences of the Artificial. Cambridge, MA: The MIT Press.

Stark, D. (2001), Ambiguous Assets for Uncertain Environments: Heterarchy is Postsocialist Firms," in P. DiMaggio (Ed.) The Twenty-First Century Firm. Princeton, NJ: Princeton University Press, pp. 69-10.4.

Watts, D.J. (1999), Small Worlds. Princeton, NJ: Princeton University Press. 
Weick, K. (1969), The Social Psychology of Organizing. New York: Random House.

White, D. and F. Harary (2001), "The Cohesiveness of Blocks in Social Networks: Node Connectivity and Conditional Density," Sociological Methodology, Inc., Boston, USA and Oxford, UK: Blackwell Publishers, Vol. 31, No. 1, pp. 305-359.

White, H.C. (2002), Markets from Networks: Socioeconomic Models of Production. Princeton, NJ: Princeton University Press.

White, H.C., S. Boorman and R. Breiger (1976), "Social Structure from Multiple Networks I: Blockmodels of Roles and Positions," American Journal of Sociology, 81, 730-779.

Williamson, O.E. (1991), "Comparative Economic Organization: The Analysis of Discrete Structural Alternatives," Administrative Science Quarterly, 36, 269-296.

Alessandro Lomi is a Professor of Management at the University of Bologna (School of Economics), and at the University of Italian Switzerland (School of Communication Sciences). His current research interests include computational model of organizations, the evolution of organizational populations and the analysis of social networks. He obtained his M.S. and PhD form Cornell University (Ithaca, New York).

Philippa Pattison is currently Head of the School of Behavioural Science and Vice-President of the Academic Board at the University of Melbourne. Her major interests are in mathematical modelling of social networks and social processes. Her current research is focussed on the developmental of dynamic network-based models for social processes, and on applications of these models to a diverse range of phenomena, including mental health, organizational design, the emergence of markets, and the spread of communicable diseases. 